Journal of Engineering and Applied Sciences 14 (8): 2701-2706, 2019

ISSN: 1816-949X

(C) Medwell Journals, 2019

\title{
Investigating the Effect of using Wasted Aluminum Strip on the HMA Characteristics
}

\author{
Hamid Athab Eedan Al-Jameel and Basim Jawad Kathim Al-Saeedi \\ Department of Civil Engineering, University of Kufa, Najaf, Iraq
}

\begin{abstract}
Million tons of wasted Coco-Cola tins are produced annually in the world, huge amount is produced, especially in Iraq. Therefore, using such wasted material has a sustainable importance for environmental. This study has focused on using strips of waste aluminum. The wasted material has been obtained from Coco-Cola tins. The wasted tins were shredded into strips. These strips have average dimensions of $5 \mathrm{~mm}$ width and 10 $\mathrm{mm}$ length. Then these strips have been added (from $0,0.5,1.0,1.5,2.0$ and 2.5\%) from the total weight of aggregate. The Marshall characteristics have been tested for reference sample $(0 \%)$ of wasted aluminum strips and other different percentages. The results indicated that using $1 \%$ of these strips give acceptable values for stability, flow and density.
\end{abstract}

$\underline{\text { Key words: HMA, waste aluminum strips, surface layer, stability, Coco-Cola tins, aggregate }}$

\section{INTRODUCTION}

In recent years there has been an increasing interest in using different admixture to construct more durable pavement for different pavement layers (i.e., subbase, base, binder and surface). A significant amount of literature has indicated the use of solid waste materials in Hot Mix Asphalt (HMA). These waste materials have been used in three folds. Firstly, they are used as modifiers to the asphalt binder (Dong and Tan, 2011; Colbert and You, 2012). Secondly, they are utilized as replacement of traditional aggregate and filler (Anderson et al., 1983; Zulkati et al., 2011; Al-Saeedi and Al-Jameel (2018). Thirdly, the waste materials have been used as additives such as polymers and fibers (Ahmadinia et al., 2012; Moghaddam et al., 2014). However, previous studies of using different admixtures for HMA have not deal with using waste aluminum strips. According to the available literature, the first attempt of using such material was implemented by Muwashee et al. (2018) but in mortar and concrete mixes not with HMA. The results indicated improving the performance for mechanical properties (compressive, tensile and flexural strengths) for both reinforced mortar and concrete mixes with waste aluminum strips up to $200 \%$ for some properties.

Ajam (2013) used a material in HMA which may be close to aluminum strips behavior in HMA. The researcher used shredded Tetra-Pak in HMA. The results showed just slightly increase in the stability of binder layer and the value of flow is out of specifications (more than $4 \mathrm{~mm}$ ) with percent of Ttra-Pak is higher than $0.5 \%$ while the percentages of Tetra-Pak ranges from $0-2 \%$.

\begin{tabular}{|c|c|c|c|c|c|}
\hline TPA (\%) & $\begin{array}{l}\text { Flow } \\
(\mathrm{mm})\end{array}$ & $\begin{array}{c}\text { Density } \\
\left(/ \mathrm{cm}^{3}\right)\end{array}$ & $\begin{array}{l}\text { Stability } \\
(\mathrm{kN})\end{array}$ & $\begin{array}{l}\text { Air voids } \\
(\%)\end{array}$ & $\begin{array}{l}\text { Voids filled } \\
\text { with asphalt }(\%)\end{array}$ \\
\hline Specifications & $2-4$ & - & 7.00 & $3-5$ & $70-85$ \\
\hline 0 & 2.53 & 2.522 & 7.25 & 3.14 & 82.30 \\
\hline 0.5 & 4.65 & 2.484 & 7.32 & 4.16 & 80.20 \\
\hline 1.0 & 6.67 & 2.460 & 7.47 & 5.64 & 78.10 \\
\hline 1.5 & 12.58 & 2.270 & 7.70 & 13.25 & 72.60 \\
\hline 2.0 & 18.96 & 2.351 & 6.39 & 12.02 & 67.50 \\
\hline
\end{tabular}

In addition, air voids and flow increase while voids filled with asphalt, stability and density decrease with increasing the percent of Tetra-Pak beyond $0.5 \%$ as indicated in Table 1.

Perhaps the most serious advantage of using waste aluminum strips resulting from Coco-Cola tins with HMA is to help protecting the green environment even if there is no significant improvement in other characteristics such as stability and flow. Then, this study aims to investigate the effect of using waste aluminum strips with HMA.

\section{MATERIALS AND METHODS}

The main step of this research is to focus on conducting Marshall tests on both control mix and mixes which have different ratios of waste aluminum strips. These percentages of waste aluminum strips are $0,1.0,1.5$, 2.0 and $2.5 \%$. These percentages from the total weight of aggregates. In addition according to several attempts using different percentages of waste strips it was found that $3 \%$ or more resulted in high value of flow which was more than acceptable limits $(>4 \mathrm{~mm}$ ) according to SCRB/R9, therefore, the above percentages have adopted in this study.

Corresponding Author: Basim Jawad Kathim Al-Saeedi, Department of Civil Engineering, University of Kufa, Najaf, Iraq 
Table 2: Properties and specification of coarse aggregate

\begin{tabular}{|c|c|c|c|c|c|}
\hline \multirow[b]{2}{*}{ Test description } & \multirow[b]{2}{*}{ Test method } & \multicolumn{3}{|l|}{ Results } & \multirow[b]{2}{*}{ Specification requirements } \\
\hline & & $12.5-19(\mathrm{~mm})$ & $9.5-12.5(\mathrm{~mm})$ & $4.75-9.5(\mathrm{~mm})$ & \\
\hline Los angeles abrasion (\%) & AASHTO (T96) & 18 & 18 & 25 & $<30$ \\
\hline Soundness $(\%)$ & AASHTO (T104) & 2.116 & 2.119 & 2.837 & $<12$ \\
\hline Specific dravity (Bulk) & AASHTO (T85) & 2.618 & 2.615 & 2.610 & - \\
\hline Flat and elongated particles (\%) & $\begin{array}{l}\text { AASHTO (M323), } \\
\text { ASTM(D4791) }\end{array}$ & 3.1 & 2.2 & 2.6 & $<10$ \\
\hline Clay lumps and friable particles (\%) & AASHTO (T112) & 0.72 & 1.04 & 1.67 & $<3$ \\
\hline Coating and stripping (\%) & AASHTO (T182) & $>95$ & $>95$ & $>95$ & $>95$ \\
\hline Percentage of fractured particles $(\%)$ & ASTM (D5821) & 90 & 90 & 92 & $>90$ \\
\hline
\end{tabular}

Table 3: Fine aggregate-physical properties and specifications

\begin{tabular}{lllc}
\hline The test & $\begin{array}{l}\text { The specification } \\
\text { of test }\end{array}$ & Results & $\begin{array}{c}\text { Specification } \\
\text { requirements }\end{array}$ \\
\hline $\begin{array}{l}\text { Liquid limit plasticity } \\
\text { index }\end{array}$ & $\begin{array}{l}\text { AASHTO (T89) } \\
\text { AASHTO (T90) }\end{array}$ & NonNon & $-<4$ \\
Specific gravity (Bulk) & AASHTO (T84) & 2.646 & - \\
$\begin{array}{l}\text { Water absorption (\%) } \\
\text { Clay lumps and friable }\end{array}$ & ASTM (C-127) & 1.53 & $<2$ \\
particles (\%) & AASHTO(T112) & 1.83 & $<3$ \\
Sand equivalent (\%) & AASHTO (T176) & 47 & $>45$ \\
\hline
\end{tabular}

Table 4: Used asphalt phy sical properties

\begin{tabular}{|c|c|c|c|}
\hline Type of test & Specification & Result & Specification limits \\
\hline $\begin{array}{l}\text { Penetration at } \\
25(1 / 10 \mathrm{~mm})\end{array}$ & ASTM (D5) & 40 & $40-50$ \\
\hline Ductility at $25(\mathrm{~cm})$ & ASTM (D113) & 140 & Min. 100 \\
\hline Softening point $\left({ }^{\circ} \mathrm{C}\right)$ & ASTM (D36) & 55 & - \\
\hline Flash point $\left({ }^{\circ} \mathrm{C}\right)$ & ASTM (D92) & +232.0 & Min. 232 \\
\hline Solubility (\%) & ASTM (D2042) & 99.5 & Min. 99.0 \\
\hline $\begin{array}{l}\text { Specific gravity } \\
\text { at } 25\left(\mathrm{~g} / \mathrm{cm}^{3}\right)\end{array}$ & ASTM (D70) & 1.03 & - \\
\hline $\begin{array}{l}\text { Kinematic viscosity } \\
\text { at } 135^{\circ} \mathrm{C} \text { (Centistokes) } \\
\text { Retained of original }\end{array}$ & $\begin{array}{l}\text { ASTM (D2170) } \\
\text { and SCRB (R9) }\end{array}$ & 710 & $>400$ \\
\hline Penetration (\%) & ASTM (D5) & 75 & $>55$ \\
\hline Ductility $(\mathrm{cm})$ & ASTM (D113) & 35 & $>25$ \\
\hline
\end{tabular}

The raw materials: The raw materials used in this study have been brought from Al-Diwaniyah Lab., in Al-Diwaniyah city which is located about $200 \mathrm{~km}$ south of Baghdad. These materials are the aggregate, filler and bitumen. Table 2 and 3 demonstrate the characteristics of both coarse and fine aggregates. These materials satisfy with the $(\mathrm{SCRB} / \mathrm{R} 9)$ for dense graded paving mixtures of surface coarse. The physical characteristics of asphalt are indicated in Table 4 . Whereas the used mineral filler characteristics have been presented in Table 5 . Accordingly, the characteristics of all used materials are within the limits of specification as indicated in Table 2-5.

The used waste aluminum strips: The waste aluminum strip was used as additives to the HMA mix. These strips were prepared from Coco-Cola tins after cutting these tins into strips with average $5 \mathrm{~mm}$ width and average $10 \mathrm{~mm}$ length as indicated in Fig. 1. Furthermore, the mechanical properties of aluminum are as indicated in Table 6.

Method of mix design: Marshall design method has been adopted in this study. This method of design is utilized to
Table 5: Mineral filler properties (SCRB/R9)

Sieve size

\begin{tabular}{llll}
\hline $\mathrm{mm}$ & In & Result & Specification \\
\hline 0.600 & $\# 30$ & 100 & 100 \\
0.300 & $\# 50$ & 100 & $95-100$ \\
0.075 & $\# 200$ & 83 & $70-100$ \\
Liquid limit & & Non & - \\
Plasticity index & & Non & $<4$ \\
Specific gravity AASHTO-T84 & 2.716 & - & \\
\hline
\end{tabular}

Table 6: Mechanical properties of the strips used in the study (Kaufman, 2000)

\begin{tabular}{llcc}
\hline Density & Tensile strength & $\begin{array}{c}\text { Modulus of } \\
\text { elasticity }\end{array}$ & $\begin{array}{c}\text { Elongation after } \\
\text { tensile test }\end{array}$ \\
\hline $\begin{array}{l}2700 \mathrm{~kg} \text { per } \\
\text { cubic meter }\end{array}$ & $\begin{array}{l}310 \mathrm{MPa} \text { (ultimate) } \\
\text { and 276 Mpa (y ield) }\end{array}$ & $70 \mathrm{Gpa}$ & $12 \%$ at break \\
\hline
\end{tabular}

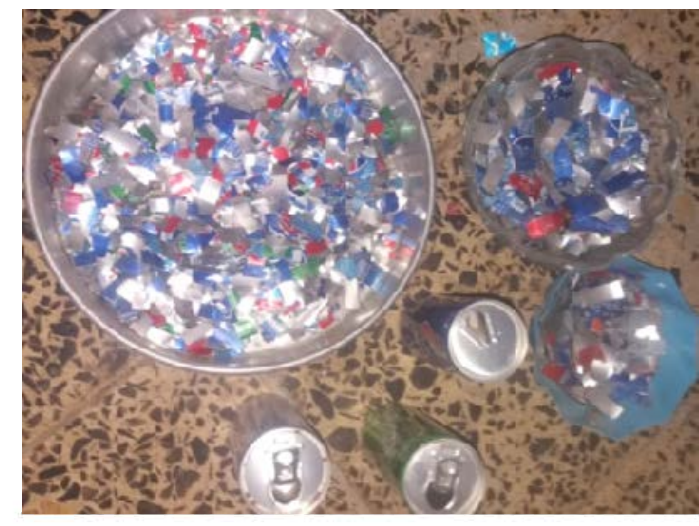

Fig. 1: Waste aluminum strips raw materials

find out the Optimum Asphalt Content (OAC) and evaluate other asphalt mixture characteristics such as stability and flow. The weight of aggregate is about $1.2 \mathrm{~kg}$ and the grade of asphalt is $40 / 50$. Then these specimens have been increased to temperatures of $130.0^{\circ} \mathrm{C}$ and $180.0^{\circ} \mathrm{C}$ by heating them. In addition, aluminum strips with various percentages of replacement from $0.0-2.5 \%$ of total weight has used. The asphalt content for all prepared mixes has been considered as a percent of weight from the total weight of the mixture. A preheated model and 75 blows on top and bottom faces of the specimen have been conducted. After compacting the samples they were permitted to cool for $24 \mathrm{~h}$ and removed from the mold 
Table 7: The characteristics of control mixture

\begin{tabular}{llc}
\hline Type of test & Results & Specification limits \\
\hline Stability $(\mathrm{kN})$ & 13.3 & Min. 8 \\
Flow $(0.25 \mathrm{~mm})$ & 2.8 & $2-4$ \\
Bulk density $(\mathrm{Gmb}),\left(\mathrm{gm} / \mathrm{cm}^{3}\right)$ & 2.343 & - \\
Air Voids in Total mix VTM), (VA) (\%) & 4.5 & $3-6$ \\
Air Voids in Mineral Aggregate (VMA) (\%) & 15 & Min.14 \\
Air Voids Filled with Asphalt (VFA) (\%) & 75 & - \\
OAC (\%) 4.6 & $4-6$ & \\
Index of retained strength (\%) & 75 & Min. 70 \\
\hline
\end{tabular}

Table 8: Marshall characteristics with different percentages of aluminum strips

\begin{tabular}{lccc}
\hline Percentage of added (\%) & Stability $(\mathrm{kN})$ & Flow $(\mathrm{mm})$ & Density $\left(\mathrm{g} / \mathrm{cm}^{3}\right)$ \\
\hline 0.0 & 13.3 & 2.9 & 2.343 \\
0.5 & 12.6 & 3.2 & 2.327 \\
1.0 & 12.0 & 3.4 & 2.288 \\
1.5 & 11.3 & 3.8 & 2.253 \\
2.0 & 8.5 & 4.2 & 2.227 \\
2.5 & 8.1 & 5.3 & 2.208 \\
\hline
\end{tabular}

using an extrusion jack. Then, the unit weight, void ratios, flow and stability tests have been achieved complying with the Marshall procedure.

OAC value: To determine the $\mathrm{OAC}$ using Marshall method, the percentages of $4,4.5,5,5.5$ and 6.0 of asphalt cement have been utilized to produce 15 samples dividing into 3.0 samples for each percentage and after that the optimum value of asphalt will be used. Based on both ASTM D6927 and AASHTO R-12, the OAC could be determined from the average values of asphalt which corresponding to the variables that indicates in Eq. 1. Table 7 demonstrates the characteristics of reference HMA and the index of retained strength:

$\mathrm{AC}$ for maximum stability $+\mathrm{AC}$ maximum density + $\mathrm{OAC}(\%)=\frac{\mathrm{AC} \text { median percent of airvoids }}{3}$

Adding aluminum strips: The $\mathrm{OAC}$ of reference mixture is $4.6 \%$ which is used for preparing the mixtures with Aluminum strips in HMA with $(0.5,1,1.5,2,2.5 \%)$ weight of total aggregate three molds for every percentage. The obtained results are indicated in Table 8 .

Calculation of volumetric properties: To investigate the effect of adding aluminum strips on VA, VFA and VMA and by using Marshall relationships and pervious data, Table 9 and 10 express the percentage of material and all volumetric properties of HMA. Bulk specific gravity of combined aggregate (Gsb) is $2.547 \mathrm{~g} / \mathrm{cm}^{3}$ (Fig. 2).

Effect of strips on Marshall characteristics: Having reported the control mix, Table 7 , the adding of strips with different percentages for the surface layer slightly decreases the stability as indicated in Table 8 about (10\%)
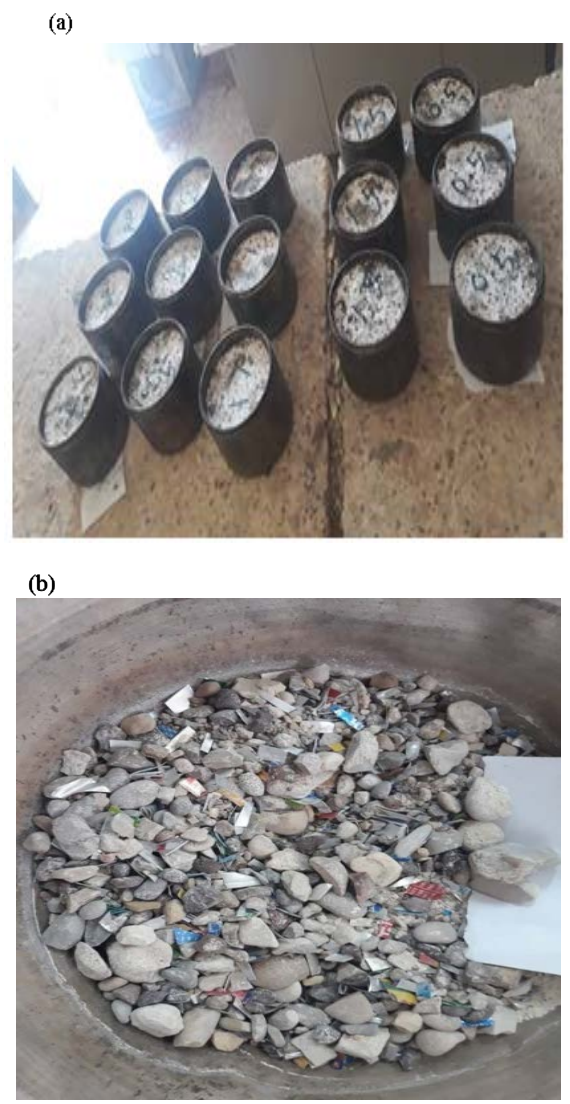

Fig. 2: a, b) Raw materials for mixes and prepared samples

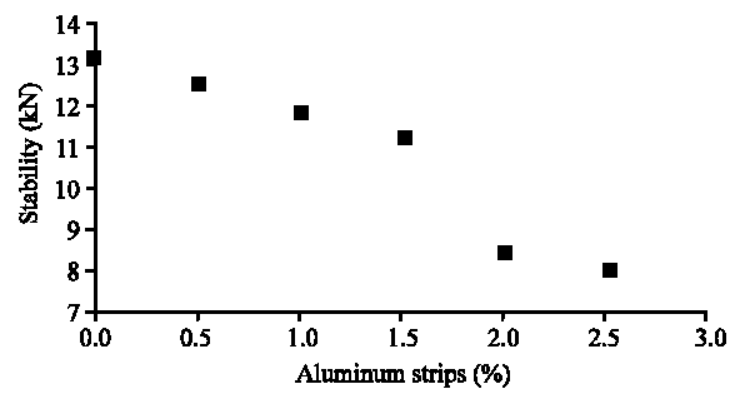

Fig. 3: Relationship between Aluminum strips and stability

at $1 \%$ additives while sharply decrease around $15-39 \%$ at 1.5-2.5 the percent of additives as shown in Fig. 3, may be the lack of interlock between particles because of existence aluminum strips lead to this behavior. Whereas the flow increases from approximately $10-83 \%$ at $0.5-2.5$ the percent of addition consequently to exceed the specification limits $(>4 \mathrm{~mm}$ ) for the percentage of equal or more than $2 \%$ of aluminum strips as indicated in Table 8 and Fig. 4 explain that. The flow unsatisfactory in 2 and $2.5 \%$ from replacement. It seems that smooth texture of aluminum may be the main reason who is responsible of reducing the cohesion in asphalt 
Table 9: Percentage of materials in HMA in $1 \%$ addition

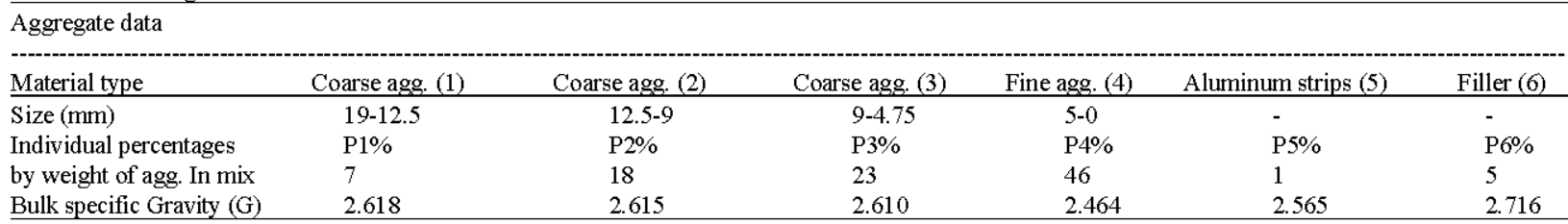

Table 10 : Volumetric properties of HMA in $1 \%$ addition

\begin{tabular}{lc}
\hline Properties & Values \\
\hline Asphalt content by weight of total mix (Ps) & 4.6 \\
Aggregate content by weight of total mix Pa $=100-\mathrm{Ps}(\mathrm{Pa})$ & 95.2 \\
Maximum specific gravity for mix. acc ording & 2.447 \\
to (ASTM D 2041) (Gmm) & \\
Bulk specific gravity of Marshall specimen & 2.288 \\
(ASTM D 2726), $\mathrm{g} / \mathrm{cm}^{3}$ (Gmb) & \\
Air Voids (VA) & 5.6 \\
\% Voids in Mineral Aggregate (VMA) & 14.3 \\
\%Voids Filled with Asphalt (VFA) & 61 \\
\hline
\end{tabular}

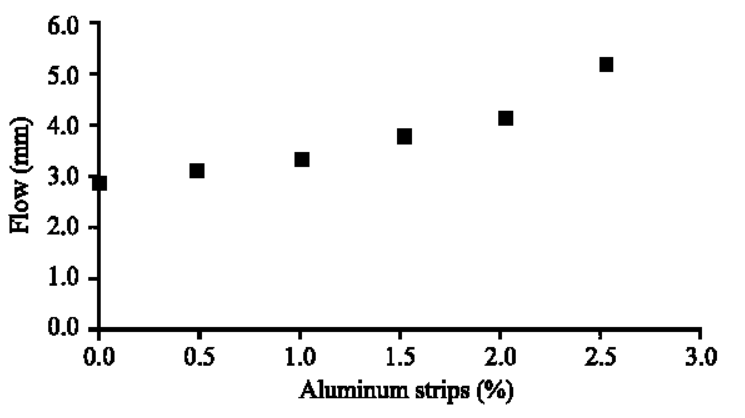

Fig. 4: Relationship between aluminum strips and flow

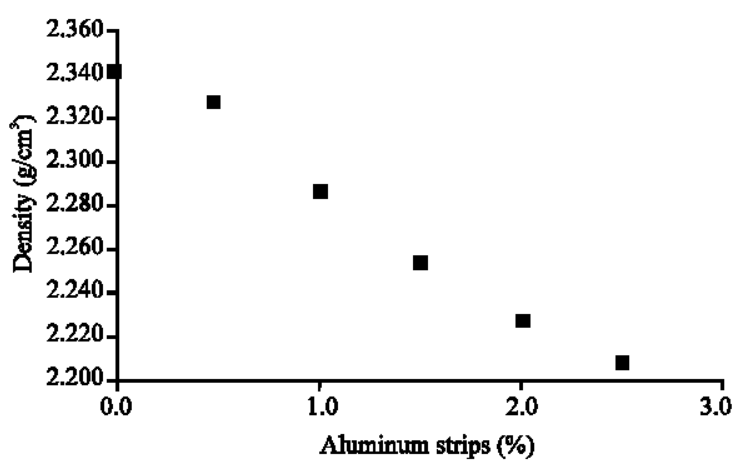

Fig. 5: Relationship between aluminum strips and density

mixture and increasing slide between the particles of mixture gradually leads to increase flow on asphalt specimens.

The inverse behavior has been noticed for the density where it drops at various rates in every increasing of aluminum strips as shown in Fig. 5. It is likely that the low specific gravity for aluminum is the main reason. The portions 0.5 and 1.5 achieve the requirement specifications but the percent $1 \%$ is the one which has to be preferred because it ensures high performance to HMA. From the available information from Table 7 and 10 , VA increase approximately $24 \%$ while VMA and VFA decrease about $5,19 \%$ consequently.

In the light of above, the results of using strips, however were not encouraging if the comparison has been made with the effect of using the same strips in concrete materials as reported by Muwashee et al. (2018). In one hand, the reason for this is not clear but it may have something to do with strip dimensions. These dimensions may be not as small as for the fiber. Therefore, this study recommends to reduce the width up to $3 \mathrm{~mm}$, however, such a process needs additional efforts to be done. On the hand these strips are likely to be more suitable with other layers such as binder and base due to the size of aggregates in these layers.

Moisture susceptibility: The presence of water has complex effect on the performance of HMA which relays on different variables. The immersion test utilizes the compressive test which was achieved according to AASHTO T167-97 as a strength parameter (Al-Saeedi and Al-Jameel, 2018). Two groups, reference mix and mix with $1 \%$ Aluminum strips content are used in this test. From each group 3 samples are immersing for period $24 \mathrm{~h}$ at $60^{\circ} \mathrm{C}$ and $2 \mathrm{~h}$ at $25^{\circ} \mathrm{C}$ in a water bath and the others are kept dry inside air bath for $4 \mathrm{~h}$ at $25^{\circ} \mathrm{C}$ where this is depended here. The retained compressive strength could be illustrated as a percentage for the ratio of conditioned compressive strength to controlled compressive strength:

$$
\text { Index of retained strength } \%=\frac{\mathrm{S} 1}{\mathrm{~S} 2}
$$

where, S1 and S2 = Compressive strength of immersed and dry specimens, respectively. Preceding results demonstrate that the percent $1 \%$ of adding the waste strips is the recommended value to be used. Therefore, this percent has been used to determine the index of retained strength. The results show that the calculated value is within the acceptable limits even this is less than the value for control mix as indicated in Table 11 . 


\begin{tabular}{llc}
\multicolumn{3}{l}{ Table 11: Results for index of retained strength } \\
\hline Items & Condition & Index of retained strength (\%) \\
\hline 1 & Reference mixture & 75 \\
2 & Adding $1 \%$ & 70 \\
\hline
\end{tabular}

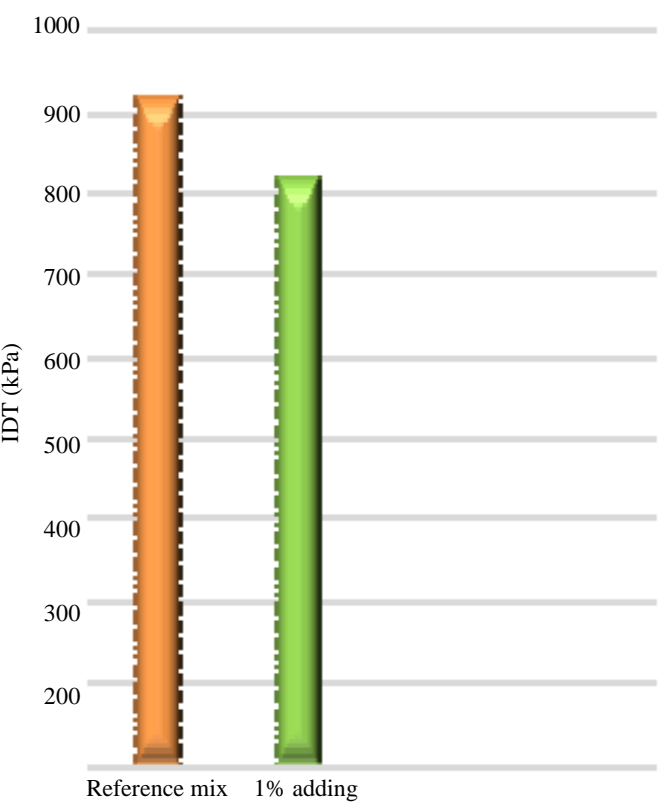

Fig. 6: Indirect tensile strength (IDT) test

\section{RESULTS AND DISCUSSION}

Indirect tensile strength of bitumen mixture: This test is stated in ASTMD 693. The specimens have been prepared with dimensions $101.6 \mathrm{~mm}$ in diameter and $63.5 \mathrm{~mm}$ in height. In addition, the two loading strips of $12.7 \mathrm{~mm}$ wide and $63.5 \mathrm{~mm}$ long are made of steel to distribute the load the parallel way. The compressive load has been applied at constant rate of two $50.8 \mathrm{~mm} / \mathrm{min}$ and the ultimate load at failure has been recorded as the specimen is loaded until failure, peak load has been measured according to the test (AASHTO-T322). Figure 6 indicates load configuration and failure plane for specimen in Indirect Tensile Strength test (ITS). The value of compressive peak load could be indirectly obtained from a sample by applying a tensile loading in the level plane. Then, according to Eq. 3, the ITS value could be determined:

$$
\mathrm{ITS}=\frac{2 \mathrm{P}}{\pi \mathrm{td}}
$$

Where:

$\mathrm{P}=$ The Peak load, expresses in $\mathrm{N}$

$\mathrm{t}=$ The height of the expressed in $\mathrm{mm}$

$\mathrm{d}=$ The diameter of the specimen $(\mathrm{mm})$

Figure 8 demonstrates the effect of using aluminum strips on IDT test comparing with IDT test for control mix.
Using 1\% of the Aluminum strips decreases the IDT value by about $100 \mathrm{kPa}$ which is still within the acceptable limit. Regarding to the previous results, one could find little reduction in mechanical characteristics such as stability, ITS and other characteristics. These reductions could be attributed to two reasons. Firstly, a possible explanation for these results may be the huge dimensions of waste aluminum strips ( $5 \mathrm{~mm}$ width and $10 \mathrm{~mm}$ length). These values are so, high comparing with fiber. Therefore, minimizing these dimensions to $3 \times 6 \mathrm{~mm}$ may give better results. Secondly, using these strips in surface layer may reduce from their influence of stability and IDT. Therefore, selecting other pavement layer such as binder and base may show good behavior.

\section{CONCLUSION}

The main important points obtained from this study could be summarized as: a huge amount of wasted CocoCola produced annually created environmental problems. Therefore, using such waste materials is one of sustainability index even with low percent of waste material. As the percentage of waste strips increases, most of the mechanical characteristics decrease. This could be attributed to the large dimensions of strips ( 1 and $2 \mathrm{~cm}$ ) comparing with fiber dimensions which are $\leq 0.3$ and $1 \mathrm{~cm}$. The prefer percent value of waste strip is $1 \%$. This value could satisfy the specifications of HMA when the stability of surface pavement $>10 \mathrm{kN}$.

\section{RECOMMENDATIONS}

According to the findings from this study, the recommendation is to minimize the dimension of strips to be $3 \mathrm{~mm}$ in width which may improve the performance of HMA with waste strips. This study would have been more relevant if it had used the waste aluminum strips with other pavement layers such as binder and base. Therefore, this study recommends of doing further study on such layers.

\section{ACKNOWLEDGEMENTS}

The researchers would like to thank AL-Qadisiya Lab staff for their incredible support in both achieving the tests and also in providing the raw materials which were used in this study.

\section{REFERENCES}

Ahmadinia, E., M. Zargar, M.R. Karim, M. Abdelaziz and E. Ahmadinia, 2012. Performance evaluation of utilization of waste Polyethylene Terephthalate (PET) in stone mastic asphalt. Constr. Build. Mater., 36: 984-989. 
Ajam, H.K.K., 2013. Utilization of shredded tetra-pak in hot mix asphalt. Al Qadisiyah J. Eng. Sci., 6: 287-293.

Al-Saeedi, B.J.K. and H.A.E. Al-Jameel, 2018. Sustainable performance of Iraqi asphalt base course using recycled glass as aggregate replacement. J. Univ. Babylon Eng. Sci., 26: 63-80.

Anderson, D.A., J.P. Tarris and D. Brock, 1983. Dust collector fines and their influence on mixture design. J. Assoc. Asphalt Paving Technol., 51: 353-397.

Colbert, B.W. and Z. You, 2012. Properties of modified asphalt binders blended with electronic waste powders. J. Mater. Civil Eng., 24: 1261-1267.

Dong, Y. and Y. Tan, 2011. Mix design and performance of crumb rubber modified asphalt SMA. Proceedings of the GeoHunan International Conference 2011 on Pavements and Materials: Recent Advances in Design, Testing and Construction, June 9-11, 2011, American Society of Civil Engineer, Hunan, China, pp: $78-86$.
Kaufman, J.G., 2000. Introduction to Aluminum Alloys and Tempers. ASM International, Russell Township, Ohio, ISBN:9780871706898, Pages: 258.

Moghaddam, T.B., M. Soltani and M.R. Karim, 2014. Evaluation of permanent deformation characteristics of unmodified and polyethylene terephthalate modified asphalt mixtures using dynamic creep test. Mater. Design, 53: 317-324.

Muwashee, R.S., H.A. Al-Jameel and Q.A. Jabal, 2018. Investigating the behavior of concrete and mortar reinforced with Aluminum waste strips. Intl. J. Eng. Technol., 7: 211-213.

Zulkati, A., W.Y. Diew and D.S. Delai, 2011. Effects of fillers on properties of asphalt-concrete mixture. J. Transp. Eng., 138: 902-910. 